une revue Gallia

Rhône-Alpes | 2008

\title{
Chambéry
}

Château des ducs de Savoie, chambre des Comptes

\section{Virginie Jolly}

\section{(2) OpenEdition \\ 12 Journals}

Édition électronique

URL : http://journals.openedition.org/adlfi/1612

ISSN : 2114-0502

Éditeur

Ministère de la culture

Référence électronique

Virginie Jolly, «Chambéry », ADLFI. Archéologie de la France - Informations [En ligne], Rhône-Alpes, mis en ligne le 01 mars 2008, consulté le 19 avril 2019. URL : http://journals.openedition.org/adlfi/1612

Ce document a été généré automatiquement le 19 avril 2019

(c) Ministère de la Culture et de la Communication, CNRS 


\section{Chambéry}

Château des ducs de Savoie, chambre des Comptes

\section{Virginie Jolly}

Identifiant de l'opération archéologique : 9803

Date de l'opération : 2008 (SP)

1 Au printemps 2008, a été réalisée une étude de bâti dans deux salles au rez-de-chaussée du « bâtiment du Gouvernement » du château des ducs de Savoie. Ces deux salles faisaient l'objet de travaux de réaménagement pour être transformées en salles d'expositions temporaires pour le conseil général de Savoie. En dépit de son importance historique et architecturale, aucune véritable étude archéologique n'avait jusqu'à ce jour porté sur le château. Seuls, quelques éléments stratigraphiques avaient été recueillis lors de surveillances de travaux en 1991 et 2007 ainsi que de sondages d'évaluation limités en 2001 et 2002.

2 Les résultats de ces nouvelles recherches archéologiques ont permis la distinction de trois phases, l'une de construction et deux autres de transformations, qui sont comprises entre la fin du XIV es. et le XXes.

3 La première se situe entre la fin du XIV $\mathrm{X}^{\mathrm{e}} \mathrm{s}$. et le $\mathrm{XV}^{\mathrm{e}} \mathrm{s}$. Elle correspond à la construction du bâtiment aujourd'hui appelé bâtiment « du Gouvernement ». Ce bâtiment de plan barlong irrégulier était constitué de trois salles en rez-de-chaussée dont seules deux ont subsisté. Sur la façade nord, une série de baies à meneaux et coussièges éclairent ces deux pièces. La salle occidentale est de grandes dimensions, cinq portes permettent de desservir les salles latérales, le couloir et l'escalier menant aux étages. La présence d'une cheminée monumentale et de placards dont l'encadrement était sculpté en débord renforce l'idée selon laquelle cette pièce servait de salle d'apparat.

4 La deuxième phase déterminée par notre étude correspond au délaissement puis à la réhabilitation de ces salles. Peu de changements sont avérés entre le XVI ${ }^{e} \mathrm{~s}$. et le XVII $\mathrm{s}$., ce qui correspond à la phase d'abandon du château par Emmanuel-Philibert et de ses successeurs. En 1730, après son abdication, le roi Victor-Amédée II se retire au château 
de Chambéry. À cette occasion et tout au long du XVIII ${ }^{\mathrm{e}}$ s., de nombreux travaux vont y être effectués et notamment dans la chambre des Comptes. Elle subit d'une part, des changements mineures comme le bouchage des placards, la destruction des coussièges et la modification des décors notamment ceux en grisaille; $d$ 'autre part des transformations majeures avec l'obstruction d'une porte, le percement d'une fenêtre, la destruction de la cheminée monumentale et l'abaissement du plafond de la première salle. La troisième et dernière phase concerne les $\mathrm{XIX}^{\mathrm{e}} \mathrm{s}$. et $\mathrm{XX}^{\mathrm{e}} \mathrm{s}$. Ce sont surtout les circulations et les surfaces des sols et murs qui sont modifiés. Dans la salle 1, quatre portes ont été obturées et trois nouvelles ont été percées en remplacement.

5 JOLLY Virginie (Archéodunum)

INDEX

Thèmes : château, construction

Index chronologique : XIVe siècle apr. J.-C., XVe siècle apr. J.-C., XVIe siècle apr. J.-C., XVIIe siècle apr. J.-C., XVIIIe siècle apr. J.-C.

operation Sauvetage programmé (SP)

Index géographique : Rhône-Alpes, Savoie (73), Chambéry

\section{AUTEUR}

VIRGINIE JOLLY

Archeodunum 